\title{
Comparative evaluation about the efficacy of the use of variable concentrations of epinephrine in Tumescent solution for control of bleeding in patients with abdominal liposuction
}

\author{
Mahtab Farhadi, Abdolreza Khorshidifar, Abdolazim Ghalambor, Alireza Bakhshaeekia
}

Department of Plastic and Reconstructive Surgery, Faculty of Medicine, Ahvaz Jundishapur University of Medical Sciences, Ahvaz, Iran

Corresponding author: Abdolreza Khorshidifar (Email: abdolrezakhorshidifar@yahoo.com)

(Submitted: 12 September 2020 - Revised version received: 29 September 2020 - Accepted: 23 - October 2020 - Published online: 26 December 2020)

\begin{abstract}
Objective: The use of epinephrine for controlling the blood loss has gained out in many dermatological surgeries; however, its use in liposuction has not been studied. In this regard, we aimed to figure out the effectiveness of using epinephrine in tumescent solution during liposuctions surgery.

Methods: In this study, we present a prospective, double-blind, non-randomized study evaluating the effects of adding epinephrine to tumescent solution intraoperative in patients undergoing liposuction. Thirty-six patients including 6 males and 29 females undergoing liposuction were divided into two groups. In case group, we use 1-1.4 mg/L epinephrine (based on the location of surgery) in tumescent solution; and control group did not receive epinephrine. Lab data such as hemoglobin and hematocrit as well as clinical data including blood pressure and heart rate were recorded before, after $1 \mathrm{~h}$, and $6 \mathrm{~h}$ of liposuction.

Results: In this study, we observed that both case and control group faced a significant drop in their hemoglobin and hematocrit levels; however, the decrement was significantly lower in case group. In addition, both groups had a stable hemostasis after $1 \mathrm{~h}$ and $6 \mathrm{~h}$ of surgery. In this regard, we did not observe any significant difference between heart rate and blood pressure of two groups.

Conclusion: The results of this study suggest that using epinephrine as vasoconstriction agent in tumescent solution might decrease the rate of bleeding and increase the chance of stable hemostasis both during and after abdominal liposuction.

Keywords: Liposuction, epinephrine, blood loss, bleeding control, hemostasis.
\end{abstract}

\section{Introduction}

Liposuction remains one of the most widely cosmetic surgical procedures and is increasingly widespread every year. ${ }^{1}$ However, since its introduction, legitimate fears over patient welfare have contributed to restrictions on the amount of fat that can be sucked. ${ }^{2-4}$ These limits are primarily determined by hemodynamic variations and blood loss that may arise during liposuction. ${ }^{4}$ Previously, it has been shown that tranexamic acid, as an anti-fibrinolytic agent, could prevent the conversion of plasminogen to plasmin in a competitive manner, and prevent the binding and degradation of fibrin and maintaining the basis of its matrix structure. ${ }^{5}$ Studies in various medical areas, such as orthopedic surgery, cardiology, and gynecology, have demonstrated that it can minimize blood loss and transfusion needs..$^{6-8}$ In recent years, the surgical use of tranexamic acid to prevent blood loss has been resurrected and the use of tranexamic acid has been co-opted by cosmetic surgeons to limit intraoperative bleeding. ${ }^{9}$ This has been found to be especially successful in burns and craniomaxillofacial and cosmetic procedures. Although several publications have cited its use in liposuction, its effectiveness in reducing pre-operative blood loss during liposuction has not yet been studied. ${ }^{10}$

On the other hand, epinephrine is the most widely used blood vessel constrictor and blood coagulation accelerator, particularly on the skin or mucous membranes to control bleeding at the site of the operation. ${ }^{6,7}$ It can reduce the absorption of local anesthetics into the bloodstream, resulting in decreased systemic toxic side effects, longer therapeutic duration of action, and decreased blood loss. ${ }^{11}$ The effect of epinephrine, with its non-selective adrenergic properties on the skin and subcutaneous tissues, in a local anesthetic solution is exerted by the constriction of local vasculatures and a decrease in local blood flow. ${ }^{8,9}$

Epinephrine, however, has serious side effects and there are some drawbacks owing to possible dose-related heart effects. ${ }^{7}$ In addition, the change in its concentration tends to have various effects on the severity of bleeding in the surgical cut. ${ }^{12}$ The optimum dosage of epinephrine for the prevention of bleeding has still not been specifically established and is controversial in dermatological surgery. ${ }^{9-12}$ This research was conducted to assess the influence of dose-dependent epinephrine supplementation in local anesthesia on intraoperative bleeding regulation, and also to assess its effects on hemodynamic properties during dermatological surgery. Based on the above-mentioned information, we aimed to figure out the effectiveness of using epinephrine in tumescent solution during liposuctions surgery.

\section{Material and Methods}

In this study, we present a prospective, double-blind, nonrandomized study evaluating the effects of adding epinephrine to tumescent solution intraoperative in patients undergoing liposuction. Thirty-six patients including 6 males and 29 females undergoing liposuction were divided into two groups ( $\mathrm{n}=18$ in each group).

In this study, inclusion criteria were as follows: patients who were referred for abdominal liposuction surgery, have a complete pre-operative examination with a history and examination without any problem or liposuction contraindication. 
In this study, liposuction surgery of the abdomen and flanks liposuction are conducted without any other surgery. All cases in both control and experimental groups are performed by the same expert cosmetic surgeon and team in one surgical center with the same lipomatic device. The body mass indexes were between 30 and 40 and the volume of transfused tumescent liquid was equal to the volume of lipid which has been aspirated from patient.

Due to the lower density of fat tissue in lower abdominal and lower risk of bleeding in this region, we used $1 \mathrm{mg} / \mathrm{L}$ of epinephrine in these cases and we add epinephrine at the dose of 1.4 and $1.2 \mathrm{mg} / \mathrm{L}$ in cases with liposuction of right/ left flanks and upper abdomen, respectively. In addition, we monitor the blood pressure and pulse rate during the surgery and every $6 \mathrm{~h}$ after surgery. Also, we routinely check anemia and hypovolemia by evaluating the hemoglobin and hematocrit before and $24 \mathrm{~h}$ after surgery to possible blood transfusion after surgery.

The data were described by frequency (percentage (\%)) or mean $\pm \mathrm{SD}$, and the comparison between the two groups was tested by $\mathrm{k}^{2}$ test. All statistical analysis was implemented in SPSS 25.0, P-values $<0.05$ were considered statistically significant.

\section{Results}

Of the 36 cases enrolled in the current study, 18 were enrolled in the control group and 18 in the control group, with a total of 7 men (19.4\%) and 29 women (80.6\%). There were 3 men (16.7\%) and 15 women $(83.3 \%)$ in the control group. In the control group, there were 4 men $(22.2 \%)$ and 14 women (77.8\%). The overall mean age of case group was $40.69 \pm 8.75$ years with a maximum age of 56 years and a minimum of 26 years. In the control group, the mean was $43 \pm 9.09$ with a maximum age of 56 and a minimum of 28 years. The mean age in case group was $38.3 \pm 7.9$ years with a maximum age of 56 and a minimum of 26 years. All details have been mentioned in the Table 1. Our results showed no significant difference alongside with these two groups regarding to age and genders (case and control, $\mathrm{P}>0.05$ )

An average of $3.5 \mathrm{~L}$ of fat has been sucked during the liposuction procedure, with a maximum of $7 \mathrm{~L}$ and a minimum of $3.5 \mathrm{~L}$. In addition, the results failed to show any significant difference between tow control and case groups $(\mathrm{P}>0.05)$.

The hemoglobin of case group was 13.2 before liposuction became 12.5 after $24 \mathrm{~h}$; and the control group had the mean hemoglobin of 12.9 before and 11.35 after surgery. The results showed a significant higher rate of hemoglobin in case group in comparison to control group after surgery but not before $(\mathrm{P}<0.05)$. Hematocrit also increased from $39.2 \%$ in the control group to 37.78 after the intervention, but in the control group hematocrit dropped from 38.68 to 34.65 after the intervention, which was also a significant difference between the two groups after intervention $(\mathrm{P}<0.05)$.

On the other hand, the systolic blood pressure in the control group increased from 124.7 to 127.5 in the first hour and dropped into 124.72 in the next $6 \mathrm{~h}$; and in the control group, the systolic blood pressure decreased from 123.33 to 120.0 in the first hour to 116.38 in the next $6 \mathrm{~h}$. The difference was not significantly different between two groups before and after surgery $(\mathrm{P}>0.05)$. In addition, the diastolic blood pressure was not statistically significant between the two groups $(\mathrm{P}>0.05)$.
In terms of heart rate, in the control group, the mean heart rate before the intervention was $83.66 \mathrm{bpm}$ and $1 \mathrm{~h}$ after the intervention was 88.61 , and $6 \mathrm{~h}$ after the intervention was 83.72; in the control group heart rate before the surgery was 79.61 and $1 \mathrm{~h}$ after was 78.61, and $6 \mathrm{~h}$ later, it was 77.5. There was no significant difference between two groups $(\mathrm{P}>0.05)$.

\begin{tabular}{|c|c|c|c|}
\hline Item & Total no. patients & Mean \pm SD & P value \\
\hline Age & 36 & $40.69 \pm 8.75$ & 0.328 \\
\hline Case & 18 & $38.3 \pm 7.9$ & \\
\hline Control & 18 & $43 \pm 9.09$ & \\
\hline Gender (M:F) & 36 & & 0.873 \\
\hline Case & 18 & $4: 14$ & \\
\hline Control & 18 & $3: 15$ & \\
\hline Hemoglobin before & 36 & & 0.491 \\
\hline Case & 18 & $13.2 \pm 1.3$ & \\
\hline Control & 18 & $12.9+1.1$ & \\
\hline Hemoglobin after & 36 & & 0.039 \\
\hline Case & 18 & $12.5 \pm 1.2$ & \\
\hline Control & 18 & $11.35 \pm 0.92$ & \\
\hline Hematocrit before & 36 & & 0.383 \\
\hline Case & 18 & $39.2 \pm 3.9$ & \\
\hline Control & 18 & $38.68 \pm 3.2$ & \\
\hline Hematocrit after & 36 & & 0.048 \\
\hline Case & 18 & $37.78 \pm 3.3$ & \\
\hline Control & 18 & $34.65 \pm 3.5$ & \\
\hline Blood pressure before & 36 & & 0.771 \\
\hline Case & 18 & $124.7 \pm 10.9$ & \\
\hline Control & 18 & $123.33 \pm 11.3$ & \\
\hline Blood pressure $1 \mathrm{~h}$ later & 36 & & 0.569 \\
\hline Case & 18 & $127.5 \pm 10.5$ & \\
\hline Control & 18 & $120.0 \pm 9.4$ & \\
\hline Blood pressure $6 \mathrm{~h}$ later & 36 & & 0.388 \\
\hline Case & 18 & $124.7 \pm 9.7$ & \\
\hline Control & 18 & $116.38 \pm 8.8$ & \\
\hline Pulse rate before & 36 & & 0.719 \\
\hline Case & 18 & $83.6 \pm 5.0$ & \\
\hline Control & 18 & $79.61 \pm 5.8$ & \\
\hline Pulse rate $1 \mathrm{~h}$ later & 36 & & 0.823 \\
\hline Case & 18 & $88.6 \pm 5.6$ & \\
\hline Control & 18 & $78.61 \pm 5.1$ & \\
\hline Pulse rate $6 \mathrm{~h}$ later & 36 & & \\
\hline Case & 18 & $83.7 \pm 5.2$ & 0.533 \\
\hline Control & 18 & $77.5 \pm 4.1$ & \\
\hline
\end{tabular}




\section{Discussion}

According to the current study, it seems that increasing the dose of epinephrine is effective in reducing bleeding due to abdominal suction; and increasing the dose of epinephrine significantly reduced the both hemoglobin and hematocrit, but this issue was seen in control as well. In addition, there was no statistically significant change in blood pressure and heart rate of the cases because these parameters might be affected by other conditions in the subject, such as pain and anxiety due to surgery.

Several randomized experiments were justified in order to offer definitive proof as to the impact of epinephrine on hemorrhage during various forms of operations. ${ }^{13-15}$ Epinephrine is a sympathomimetic amine with beta-adrenergic agonist receptor effects. Various arterioles, particularly in the skin and mucosa, exhibit vasoconstriction due to the prevailing stimulation of the a-receptor. ${ }^{4}$ The minimum dosage of epinephrine to achieve sufficient and minimal toxic effect on hemostasis is yet to be specifically defined in dermatological surgery. Few experiments remain in the literature to determine the optimum dosage of epinephrine in human subjects. In this regard, previous studies have shown that local anesthetics with 1:100,000 epinephrine, have been suggested to be consistent of sufficient vasoconstriction. ${ }^{16}$ Regulation of the dosage of epinephrine as a vasoconstrictor not only decreases the magnitude of unintended results, but can also decrease intraoperative bleeding. ${ }^{17}$

Epinephrine in combination with local anesthetic solution has been found to minimize perioperative bleeding from surgical wound sites in a variety of surgical environments. ${ }^{18-20}$ It has been shown that the 1:50,000 dose of epinephrine can have the highest hemostasis when used as an infiltration injection. ${ }^{21}$ However, owing to its rebounding activity and systemic cardiovascular side effects such as tachycardia, it can be used sparingly. ${ }^{22}$ In our research, hemodynamic changes such as heart rate and systolic blood pressure were not observed following surgery. Also, in the current study, no side effects were observed due to increasing the dose of epinephrine, and also considering the cheapness and availability of this drug in terms of cost-effectiveness, it seems reasonable to use a higher dose of this drug depending on the surgeon. Major hemodynamic changes, especially hypotension, have been reported in a lidocaine-receiving community with 1:200,000 epinephrine. However, these improvements were found to have lasted no longer than 4 min. ${ }^{23}$ In another analysis of 3rd- to 6th-min heart rate, systolic arterial pressure from 3rd- to 5th-min and diastolic arterial pressure from 2 nd- to 6 th minute following local injection were both higher in patients with higher epinephrine concentrations. ${ }^{24}$

Overall, this study showed that using epinephrine is safe in liposuction surgery when used with tumescent solution. This issue could decrease the rate of blood transfusion to reduce the viral and bacterial infection, and increase the economically and psychologically imposed on the patient.

\section{Conclusion}

The results of this study suggest that using epinephrine as vasoconstriction agent in tumescent solution might decrease the rate of bleeding and increase the chance of stable hemostasis both during and after abdominal liposuction.

\section{References}

1. Folwaczny C, Heldwein W, Obermaier G, Schindlbeck N. Influence of prophylactic lo-cal administration of epinephrine on bleeding complications after polypectomy. Endoscopy 1997;29:31-3.

2. Koay J, Orengo I. Application of local anesthetics in dermatologic surgery. Dermatol Surg 2002;28:143-8.

3. Fink BR, Aasheim GM, Levy BA. Neural pharmacokinetics of epinephrine. Anesthesiology 1978;48:263-6.

4. Dunlevy TM, O'Malley TP, Postma GN. Optimal concentration of epinephrine for vasoconstriction in neck surgery. Laryngoscope 1996;106:1412-4.

5. Pallasch TJ. Vasoconstrictors and the heart. J Calif Dent Assoc 1998;26:668-76.

6. Brown RS, Rhodus NL. Epinephrine and local anesthesia revisited. Oral Surg Oral Med Oral Pathol Oral Radiol Endod 2005;100:401-8.

7. Milam SB, Giovannitti JA Jr. Local anesthetics in dental practice. Dent Clin North Am 1984;28:493-508.

8. O'Malley TP, Postma GN, Holtel M, Girod DA. Effect of local epinephrine on cutaneous blood flow in the human neck. Laryngoscope 1995;105:140-3.

9. Santos CF, Modena KC, Giglio FP, Sakai VT, Calvo AM, Colombini BL, et al. Epinephrine concentration (1:100,000 or 1:200,000) does not affect the clinical efficacy of $4 \%$ articaine for lower third molar removal: a doubleblind, randomized, crossover study. J Oral Maxillofac Surg 2007;65:2445-52.

10. Sisk AL. Comparison of etidocaine and lidocaine for control of intra- and post-operative bleeding and pain. J Oral Maxillofac Surg 1986;44:16-20.

11. Agresti A. Categorical Data Analysis. 2nd ed. Boston: John Wiley \& Sons, 2002.

12. Guinard JP, Carpenter RL, Morell RC. Effect of local anesthetic concentration on capillary blood flow in human skin. Reg Anesth 1992;17:317-21.

13. Cansanção AL, Cansanção AJ, Cansanção BP, Vidigal RA. Lipoabdominoplasty in obese patients: Is it safe? Has good results? Plast Reconstr Surg. 2015;136(Suppl):93-94.

14. Rajesparan K, Biant LC, Ahmad M, Field RE. The effect of an intravenous bolus of tranexamic acid on blood loss in total hip replacement. J Bone Joint Surg Br. 2009;91:776-783.

15. Amer KM, Rehman S, Amer K, Haydel C. Efficacy and safety of tranexamic acid in orthopaedic fracture surgery: A meta-analysis and systematic literature review. J Orthop Trauma 2017;31:520-525.

16. Horrow JC, Hlavacek J, Strong MD, et al. Prophylactic tranexamic acid decreases bleeding after cardiac operations. J Thorac Cardiovasc Surg. 1990;99:70-74

17. Gai MY, Wu LF, Su QF, Tatsumoto K. Clinical observation of blood loss reduced by tranexamic acid during and after caesarian section: A multi-center, randomized trial. Eur J Obstet Gynecol Reprod Biol. 2004;112:154-157.

18. Tang YM, Chapman TW, Brooks P. Use of tranexamic acid to reduce bleeding in burns surgery. J Plast Reconstr Aesthet Surg. 2012;65:684-686.

19. Murphy GR, Glass GE, Jain A. The efficacy and safety of tranexamic acid in cranio-maxillofacial and plastic surgery. J Craniofac Surg. 2016;27:374-379.

20. Nair AS, Sriprakash K, Nirale AM, et al. Large volume lipo-suction: Perioperative considerations. Int J Sci Res Publications 2013;3:1-4

21. Nair AS, Verma S. Use of tranexamic acid in megaliposuction. Int J Pharm Pharm Sci. 2015;7:8.

22. Ors S, Ozkose M. Late postoperative massive bleeding in septorhinoplasty: A prospective study. Plast Surg (Oakv.) 2016;24:96-98.

23. Butz DR, Geldner PD. The use of tranexamic acid in rhytidectomy patients. Plast Reconstr Surg Glob Open 2016;4:e716.

24. Ausen K, Fossmark R, Spigset O, Pleym H. Randomized clinical trial of topical tranexamic acid after reduction mammoplasty. Br J Surg. 2015;102:1348-1353.

This work is licensed under a Creative Commons Attribution-NonCommercial 3.0 Unported License which allows users to read, copy, distribute and make derivative works for non-commercial purposes from the material, as long as the author of the original work is cited properly. 